IZA DP No. 8974

Culture of Trust and Division of Labor

Stephan Meier

Matthew Stephenson

April 2015

Forschungsinstitut

zur Zukunft der Arbeit

Institute for the Study

of Labor 


\title{
Culture of Trust and Division of Labor
}

\author{
Stephan Meier \\ Columbia University \\ and IZA \\ Matthew Stephenson \\ Columbia University \\ Discussion Paper No. 8974 \\ April 2015 \\ IZA \\ P.O. Box 7240 \\ 53072 Bonn \\ Germany \\ Phone: +49-228-3894-0 \\ Fax: +49-228-3894-180 \\ E-mail: iza@iza.org
}

\begin{abstract}
Any opinions expressed here are those of the author(s) and not those of IZA. Research published in this series may include views on policy, but the institute itself takes no institutional policy positions. The IZA research network is committed to the IZA Guiding Principles of Research Integrity.

The Institute for the Study of Labor (IZA) in Bonn is a local and virtual international research center and a place of communication between science, politics and business. IZA is an independent nonprofit organization supported by Deutsche Post Foundation. The center is associated with the University of Bonn and offers a stimulating research environment through its international network, workshops and conferences, data service, project support, research visits and doctoral program. IZA engages in (i) original and internationally competitive research in all fields of labor economics, (ii) development of policy concepts, and (iii) dissemination of research results and concepts to the interested public.
\end{abstract}

IZA Discussion Papers often represent preliminary work and are circulated to encourage discussion. Citation of such a paper should account for its provisional character. A revised version may be available directly from the author. 


\section{ABSTRACT \\ Culture of Trust and Division of Labor}

Firms exhibit heterogeneity in size, productivity, and internal structure, and this is true even within the same industry. It has been thought since the time of Adam Smith that a firm's internal structure affects its productivity through the channel of gains from specialization. Our paper provides evidence of a link between an organization's culture - specifically the trust environment - and its internal structure. We show experimentally that exogenously imposed culture endogenously leads to variation in organizational form. We prime trust using past performance from a pilot study and demonstrate that the level of trust within an organization affects division of labor and consequently organizational productivity. This evidence is consistent with a cross-country link between trust and the division of labor that we observe in data from the European Social Survey. Our results point to a mechanism that can help explain existing results on the connection between generalized trust and growth. It also points to an important determinant of a firm's internal structure: corporate culture (of trust).

JEL Classification: C90, D20, D03

Keywords: $\quad$ trust, division of labor, organizational structure

Corresponding author:

Stephan Meier

Graduate School of Business

Columbia University

710 Uris Hall

3022 Broadway

New York, NY 10027

USA

E-mail: sm3087@columbia.edu

\footnotetext{
* We thank Evan Rawley, Damon Phillips, Phanish Puranam, Ernst Fehr, Bruce Kogut, Ko Kuwabara, Ernesto Reuben, Marlo Raveendran and participants at various workshops and conferences for very valuable comments.
} 


\section{Introduction}

Firms differ substantially in size, productivity, and internal structure. For example, in some organizations the division of labor is extensive while in other it is not. While it has been known since Adam Smith's time that an organization's internal structure, e.g. the degree of division of labor, may profoundly affect its productivity, the process by which such structure evolves is less understood. Part of an organization's internal structure may be determined by its industry, but there exist substantial differences in organizational structures even within an industry (Alamazan and Molina 2005; Porter 1979.) Explaining differences in firms' organizational structures is an important aspect of explaining differences in productivity differences. ${ }^{1}$

This paper investigates whether some of the difference in organizational structure can be traced back to corporate culture. In particular, we argue and show empirically that changing an organization's level of trust affects its division of labor and thus that exogenously imposed differences in culture endogenously lead to different organizational forms. Existing literature suggests that corporate culture might play an important part in explaining firms' performance (Sørensen 2002) and that trust is crucial for cooperation within organizations (Fehr, Kirchsteiger \& Riedl 1998; Fehr \& List 2004). We want to extend those two strands of literature by arguing that the effect of trust as one dimension of corporate culture on firm's performance is partly through its effect of organizational structure, in particular the degree of division of labor. Theoretically, a link between trust (culture) and the division of labor (organizational structure) is evident when considering that the division of labor is limited by coordination costs, one of which is "whether workers trust each other" (Becker \& Murphy, 1992: p. 303).

To provide some intuition on how trust affects the division of labor, consider the example of a group of co-authors specializing in different sections of a paper. This can be efficient because 1) the person doing the literature review and write-up does not need to spend time decoding the proofs, re-focusing, and/or physically going from the field to the computer lab; and 2) that same writer has familiarized herself with relevant literature, major papers, and authors to an extent beyond that of her co-authors. Meanwhile, her co-authors have done the same mutatis mutandis. This efficiency has come at the expense of, for instance, the writer's ability to understand and improve the proofs in the formal model that another

\footnotetext{
${ }^{1}$ The organization of a firm has been argued to depend on many factors, including strategy (e.g., Chandler 1962), technology (e.g., Woodward et al. 1965), and environment (e.g., Lawrence \& Lorsch, 1967, Wan \& Hoskisson, 2003). Additionally, factors such as identity (Kogut \& Zander, 1996; Santos \& Eisenhardt, 2005), social comparison (Nickerson \& Zenger, 2008), and reciprocity (Akerlof, 1982; Fehr et al., 1998) can affect the organization and function of firms.
} 
co-author has been developing. Division of labor thus imposes an evident cost, and in a case where the value of the product is effectively the minimum effort in each subtask — so that a paper with a thorough literature review but a non-functioning model is not publishable - the cost can be great. $^{2}$

In light of such a cost we think the existence and sustainability of division of labor depend on whether the workers trust one another. ${ }^{3}$ In the absence of trust, they can lose efficiency switching between tasks, thereby "de-specializing" the group. ${ }^{4}$ An evocative example of this phenomenon set in a firm comes from management guru Stephen Covey, who describes a circumstance in which a division he managed depended on another division to help meet a customer's needs. Because Covey believed that this other division had a bad reputation, he opted to take the "easy but expensive way out" by doing everything within his division, "creat[ing] our own redundant systems". He added that "the whole organization was taxed for it in terms of the time and effort we had to put into something that should have been done by somebody else" (Covey 2006, p. 264). The firm Covey worked in had a formal division of labor but the workers endogenously compromised the presumed efficiency of this arrangement due to a lack of trust.

The question of the impact of trust on the division of labor is difficult to study empirically since, first, data on trust levels within a large number of firms and their degrees of division of labor is difficult to obtain, and, second and more importantly, a correlation between trust and division of labor could be due to omitted variables, e.g. the management team puts in place structure or institutions that affect both trust levels and division of labor. Reverse causality, i.e. the organizational structure affecting trust levels, makes it almost impossible to interpret a correlation between trust and division of labor as causal. Due to this problem, we provide two types of complementary evidence for the link between trust and division of labor. The main evidence comes from a laboratory experiment that establishes a causal effect between trust and division of labor. ${ }^{5}$ We also use cross-country evidence to establish a correlation between trust and division of labor.

In the laboratory experiment, individuals engage in a productive enterprise in groups of three and they are given the ability to alter how they divide labor among specialist and generalist task allocations. Each group's payoffs are derived from a minimum-effort production process. Individuals can all specialize on

2 This example draws on Smith's classical treatment of gains from specialization, with the efficiencies corresponding to 1) saving on switching costs and 2) the increase in skill via "learning by doing." Smith identifies a third efficiency - the creation of productive tools - but this is outside the scope of our paper.

${ }^{3}$ For a more detailed discussion of how we discuss trust, see the conceptual section 2.

${ }^{4}$ That is to say that trust affects task allocation. We focus here on "endogenous" task allocation by measuring actual effort provision in tasks, though delegation-based task allocation is also very important and plausibly affected by trust. For a review of these foundational concepts, see Puranam et al. (2013).

${ }^{5}$ For experimental methods used in answering questions in organizational studies and strategy, see Puranam et al. (2006), Camerer \& Weber (2013), Croson et al. (2007), and Chatterji et al. (2014). 
their own task and if they do they will be maximally productive as a group. However, individuals are also given the ability to engage in a non-specialized task, which comes at a productivity cost but also confers the advantage of ensuring that non-specialized task is completed to some standard. This game effectively models the real world division of labor situations we describe above, in which members of a team can choose to "de-specialize" at a cost. Before the individuals engage in the real effort task we randomly manipulate their level of trust, allowing us to study whether exogenously changing a culture of trust endogenously creates different levels of division of labor.

Our laboratory findings show a significant effect of exogenously imposed trust on specialist behavior at the intensive and extensive margins. Specifically, we find positive and significant effects of trust on the level of realized specialization within a group, as well as the total performance of the group. Exogenously changing the trust level across our organizations, i.e. our groups of three, leads to the emergence of different forms of working together, i.e. extent of division of labor. We find that even exogenously imposed trust levels can minimize uncertainty about other co-workers. Furthermore, by repeating this experiment with feedback, we observe that these effects intensify over time, with high-trust groups increasing in specialization over time.

Suggestive cross-country evidence-using data from the European Social Survey- supports this finding in that the level of generalized trust within a country corresponds to a higher level of specialization within that country's industries. The correlation between our proxy of division of labor-a measure of specialized job descriptions within a country's industries - and generalized trust is robust to economic controls and country and time fixed effects. While the evidence cannot be interpreted as causal, it supports the experimental evidence by showing that trust level is correlated to the division of labor in observational data.

Our study makes at least three important contributions to the literature:

First, our paper contributes to the debate about the effect of culture on organizational structure. A recent paper by Bloom et al. (2012b) finds that trust is associated with larger firm size and a flattening of hierarchical structures within the firm. We test a distinct but complementary theory: that trust affects the task allocation within firms, with higher-trust environments endogenously producing more specialized task allocations. The trust environment within a firm is an important feature of a company's culture (Kreps 1990), and we find that this can help a firm to facilitate a stable division of labor.

Important works by Puranam and Vanneste (2009), Poppo and Zenger (2002), and Gullati and Nickerson (2008) have investigated the impact of trust on governmental structures within firms. While we 
do not treat governance explicitly in our work, we consider our paper as complementary to this stream of research in investigating the emergence and stability of productive structures as a function of trust. Our paper can therefore be seen as a contribution to the literature of the 'micro-structural' approach to organization design (Puranam, 2014).

The division of labor is thought to be paramount in accounting for the productivity of organizations going back to Adam Smith. However, the process by which the division of labor emerges has received, to the best of our knowledge, limited prior attention in the scholarly literature. Raveendran et al. (forthcoming) constitutes a rare recent exception, focusing on factors that precipitate and sustain the division of labor. ${ }^{6}$ Our study shows that initial difference in trust level can endogenously lead to different degrees of specialization within an organization. These initial differences are important for three reasons: 1) Firm structure is inertial (Nelson, 1991), so the early structure of an organization remains important even as a firm grows in size, 2) A firm's culture is formed early and is difficult to change (Schein 2010), and 3) Trust only increases by a small amount as a function of relationship duration, so the existence of relationships among individuals within a firm does not by itself impact trust substantially over time (Vanneste et al., 2014).

Second and related to the first contribution, our paper can shed light on a mechanism explaining the relationship between trust and growth. Trust levels within a country have been thought to affect a number of economic variables, most notably growth. A number of studies show a significant correlation between trust and economic growth (e.g., Knack \& Keefer 1997 and Algan \& Cahuc (2010)). However, the precise mechanism through which trust affects growth is still an open question. Our evidence shows that a potential mechanism for the relationship between trust and growth is the organization of firms. If trust affects the division of labor as we observe in our study, and the division of labor affects the "wealth of nations" (as argued since the times of Adam Smith), this illuminates a plausible mechanism that links trust to growth: organizational structure.

Third, we contribute to the literature on the relationship between trust and economic behavior. There exists significant (mostly experimental) work on the ways in which institutions and organizational forms causally foster the trusting and trustworthy behavior of individuals (Glaeser et al., 2000; Fershtman \& Gneezy 2001; Bohnet et al 2008; Meier et al, 2014; Falk \& Zehnder, 2013). Our contribution lies in studying the converse of this research: addressing the manner in which individual's trust-levels causally

\footnotetext{
${ }^{6}$ Vernon Smith and coauthors also have several experimental papers that importantly investigate aspects of the division of labor. They explore the role of specialization in the formation of long-distance trade under different institutional environments (Kimbrough et al. 2008), the discovery and emergence of specialization (Crockett et al. 2009), and the emergence of property rights due to specialization and gains from exchange (Kimbrough et al. 2009).
} 
impact institutions and organizational forms. The only other paper that we are aware of that studies the effect of trust on economic behavior is by Bartling et al. (2013). This paper applies a very similar manipulation of high and low trust to the one we use, but investigates the role of trust and trustworthiness in inducing high and low effort equilibria in a gift exchange game, whereas we study the role of trust in the division of labor.

The paper proceeds as follows: Section 2 presents illustrative evidence from cross-country data on the relationship between generalized trust and division of labor. Section 3 includes a brief discussion of concepts and the ways they are used within the paper. Section 4 introduces the experimental design and the results of the experiment are exhibited in Section 5. Section 6 provides concluding thoughts and suggestions for further research.

\section{Illustrative Evidence on Trust and Division of Labor across Countries}

In order to motivate the relevance of our idea and experimental results outside the lab, we present crosscountry evidence from a repeated panel survey that sheds light on the relation between trust levels and division of labor. A culture of trust in a country can affect a firm's structure for at least two reasons: First, the level of trust within a mature firm can act as a constraint to forms of organization, such as divisionalization and team-production. Thus a change in the level of trust within the firm may restrict or enable structural forms. A firm may prefer an efficient team-based production arrangement with high levels of specialization but they may be constrained by the trust environment that causes the employees to prefer generalist production. Hence we have a within-country hypothesis suggesting that the division of labor will respond to changes in trust. Secondly, the nascent structure of a firm is often team-production (Alchian \& Demsetz 1972) and, because firm structure is inertial and resistant to change (Nelson 1991), trust's effects on division of labor at the team level could be expected to persist. Thus we would predict a cross-sectional correlation between trust and the division of labor. While we find support for both hypotheses, the evidence has to be taken as illustrative since, though we control for time-invariant factors on the country level, the structure of the data cannot exclude that omitted time-variant factors on the country level can explain the correlation. Nor can it account for a "reverse causation" hypothesis and thus the results can only be interpreted as correlational. We therefore couple these findings with our experimental evidence investigating the causal effect of trust on division of labor. Nevertheless, the evidence provided in this section resembles evidence on trust and growth (Knack \& Keefer, 1997; Algan $\&$ Cahuc, 20102) and we see it as a complementary illustration to our experimental evidence. 
Data sets: We draw on data from the European Social Survey (ESS) for the available years of 20022012. The range provides 217,250 individual observations drawn from 35 countries $^{7}$. We then pair this data with country-level economic measures from the Penn World Tables (Feenstra et al., 2013).

Proxy for division of labor: We exploit a unique feature of the data in the European Social Survey (ESS) to construct a measure of division of labor. The ESS contains classifications for both an individual's occupation as well as the industry in which they are employed, using the International Standard Classification of Occupations (ISCO-88) and Nomenclature of Economic Activity (NACE) codes respectively. Within our sample we have 492 unique ISCO-classified occupations and 91 NACEclassified industries. Using this data we use an idea from Gibbs and Poston (1975) and construct an index of division of labor, $d$, for each industry $j$ within a country from this data as follows (for more details, see Appendix II):

$$
d_{j}=1-\frac{\sum_{i=1}^{n} x_{i j}^{2}}{\left(\sum_{i=1}^{n} x_{i j}\right)^{2}}
$$

Where $\mathrm{n}$ is the number of possible occupations and $\mathrm{x}$ is the number of individuals in that occupation. This form is maximized when $\mathrm{x}$ is constant for all $\mathrm{i}$, suggesting a uniform distribution of individuals among the possible occupations within an industry. If we suppose that each possible occupation within an industry is a "bucket" which can be filled by employees, $d$ measures how levelly those buckets are filled within a country's given industry. As described above, our division of labor index $d$ is computed for each year within a domestic industry. That is, within a country, each industry has a unique division of labor score for a given year of the ESS.

To provide intuition on this measure, consider the forestry industry in Greece and Finland. These countries differ substantially in generalized trust, with Finland having a high average and Greece a low one. We also observe that Greece and Finland have different occupational structures within their forestry industries: a majority (61\%) of Greek forestry workers classify their occupation as "manufacturing laborer", a classification which denotes no obvious specialized skill. Compare this with Finland, in which there are no observed "manufacturing laborers" but instead there are "wood processing plant operators", "wood products machine operators", "wood treaters", "woodworking machine setters", "motorized forestry plant operators", "lifting truck operators" and so on. Moreover, these occupations are flatly

\footnotetext{
${ }^{7}$ Austria, Belgium, Bulgaria, Croatia, Cyprus, Czech Republic, Denmark, Estonia, Finland, France, Germany, Greece, Hungary, Iceland, Ireland, Israel, Italy, Kosovo, Latvia, Lithuania, Luxembourg, Netherlands, Norway, Poland, Portugal, Romania, Russian Federation, Slovakia, Slovenia, Spain, Sweden, Switzerland, Turkey, Ukraine, and the United Kingdom.
} 
distributed in the Finnish sample and no clear majority occupation is evident. As we would expect, these observations are reflected in the industry $d$ score, within Finland's forestry industry being much higher than Greece's. We maintain that it is the differentiation of skills and specific tasks that form the basis on which a worker chooses to either classify themselves as a general laborer or a machine operator. ${ }^{8}$ Thus our measure $d$ appears to be capturing an element of division of labor within industries.

Trust measure: The ESS includes a measure of trust. It is based on the question "Generally speaking would you say that most people can be trusted or that you need to be very careful in dealing with people". Responders provide an answer on a 10-point scale with the lowest category being "You can't be too careful" and the highest "Most people can be trusted". The mean response to the generalized trust question in our sample is 4.83 with a standard deviation (s.d.) of .986, and a range of 2.7-6.9. ${ }^{9}$

\section{Results:}

We evaluate the relationship between the division of labor and trust using the measures described above. Figure 1 displays the results for the aggregated $d$ scores plotted against generalized trust at the country level with a linear fit line projected on the data. Trust and $d$ are positively correlated $(p<.01)^{10}$ and indicating that an increase of one s.d. in measured trust results in a .5 s.d. increase in the observed $d$ score.

\footnotetext{
${ }^{8}$ So a worker charged with the task of treating the wood, driving the truck, and setting the machine for operation should be more apt to describe their occupation in general terms ("laborer") than a worker whose entire job consists of treating wood.

${ }^{9}$ These statistics are reported at the country level.

${ }^{10}$ Results in this section are from an OLS regression unless otherwise specified.
} 


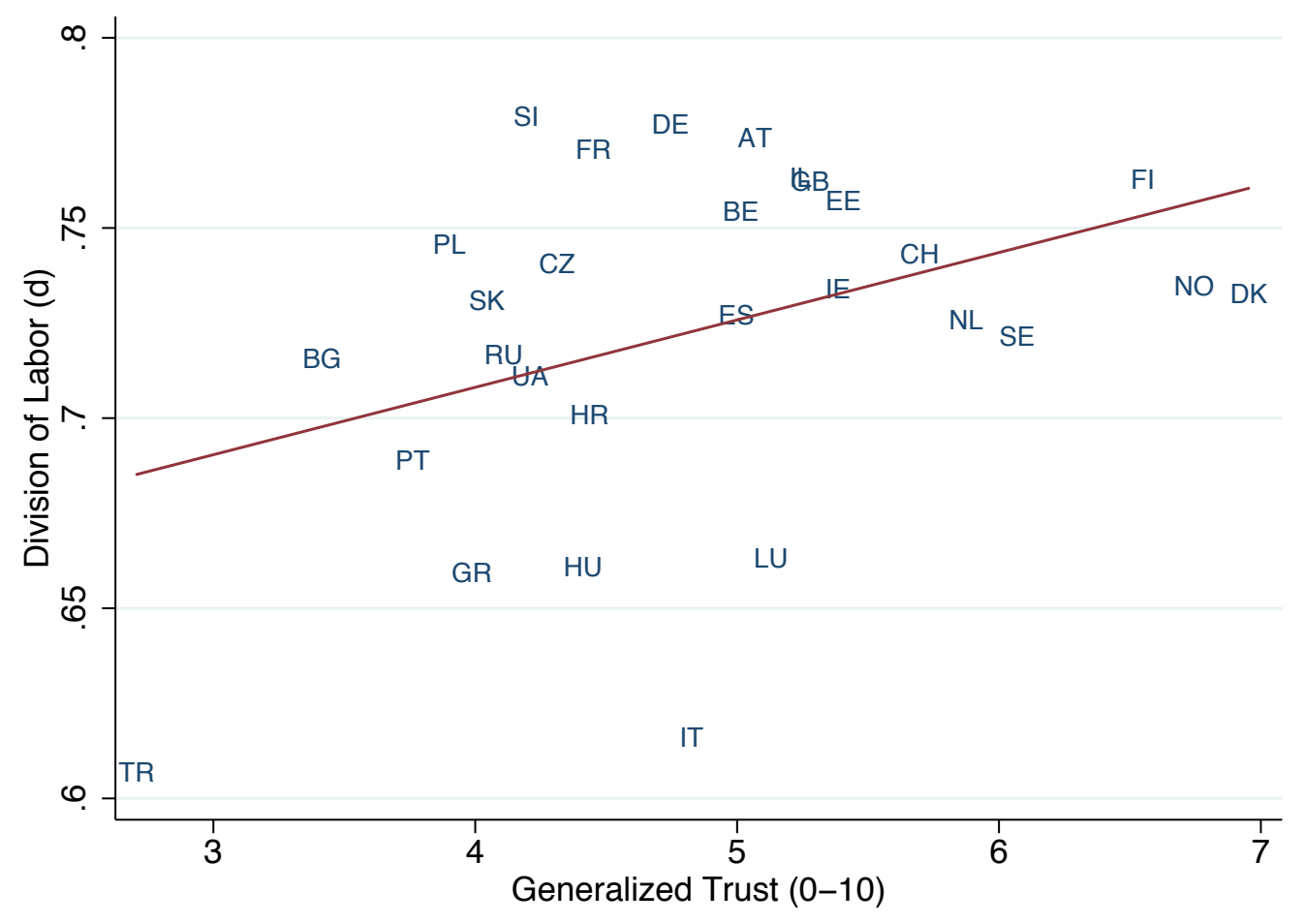

Note: Data taken from European Social Survey and measures averaged across countries from 2002-2012. Plot omits graphical outliers Cyprus (CY), Israel (IS), and Kosovo (XK). These countries are not omitted from the statistical analysis.

\section{FIGURE 1: TRUST AND DIVISION OF LABOR ("d")}

In Table 1 we explore the robustness of the association between trust and division of labor by making use of the panel structure of our data and fitting several models with a variety of controls. ${ }^{11}$ The specification controls for growth, the number of industries in a country, population, government consumption, openness, and fossil fuel consumption. Column 1 reports results on a model which considers the smallest unit of analysis given our data: the yearly domestic industry. Note that trust is still measured at the year-country level, and so the estimates reflect changes at the domestic industry level as a response to changes in the country-wide trust environment. Controlling for time-invariant effects at the domestic industry level, we observe significant positive effects of trust on division of labor. Column 2 reports results with the same controls but pooling industries within countries and years and we find a similarly significant and positive relationship between trust and the division of labor controlling for

\footnotetext{
${ }^{11}$ Appendix III exhibits a table with between-country models, including a Tobit regression.
} 
country and time fixed effects. Column (2) reports the lowest coefficient, but still indicates that a one s.d. change in log trust results in a .45 s.d. change in the division of labor.

TABLE 1 -TRUST AND THE DIVISION OF LABOR IN THE ESS DATASET

\begin{tabular}{lllll}
\hline \hline & $(1)$ & $(2)$ & $(3)$ & $(4)$ \\
Dependent Variable & $d$ & $d$ & diffd & diffd \\
\hline \multirow{2}{*}{ Log Trust } & & & & \\
& $0.160^{* * *}$ & $0.158^{* *}$ & $0.167^{* * *}$ & $0.164^{* *}$ \\
Industries/Country & $(0.0510)$ & $(0.0736)$ & $(0.0494)$ & $(0.0638)$ \\
& $-0.00698^{* * *}$ & $-2.45 \mathrm{e}-05$ & $-0.00305^{* *}$ & 0.000355 \\
Log GDP & $(0.00130)$ & $(0.00246)$ & $(0.00124)$ & $(0.00202)$ \\
& -0.00284 & -0.00744 & -0.00398 & -0.00716 \\
Log Population & $(0.00439)$ & $(0.00758)$ & $(0.00415)$ & $(0.00674)$ \\
& $-0.0275^{* *}$ & $-0.282^{*}$ & $-0.0360^{* * *}$ & -0.149 \\
Gov't Consumption & $(0.0109)$ & $(0.162)$ & $(0.0104)$ & $(0.206)$ \\
& $0.00451^{* *}$ & $-0.00586^{*}$ & $0.00492^{* *}$ & -0.00295 \\
Openness & $(0.00221)$ & $(0.00296)$ & $(0.00209)$ & $(0.00293)$ \\
& $-0.0410^{* *}$ & -0.0760 & $-0.0555^{* * *}$ & $-0.0921^{*}$ \\
Fuel Consumption & $(0.0202)$ & $(0.0511)$ & $(0.0195)$ & $(0.0473)$ \\
& $0.00368^{* * *}$ & 0.00288 & $0.00415^{* * *}$ & 0.00221 \\
Time FE & $(0.000630)$ & $(0.00201)$ & $(0.000592)$ & $(0.00155)$ \\
Country FE & $\mathrm{Y}$ & $\mathrm{Y}$ & $\mathrm{Y}$ & $\mathrm{Y}$ \\
Country Ind. FE & $\mathrm{N}$ & $\mathrm{Y}$ & $\mathrm{N}$ & $\mathrm{Y}$ \\
$\mathrm{N}$ & $\mathrm{Y}$ & $\mathrm{N}$ & $\mathrm{Y}$ & $\mathrm{N}$ \\
\hline \hline
\end{tabular}

Note: Data from the European Social Survey, 2002-2012. Results from an OLS multiple regression, robust errors clustered at the domestic industry ( 1 and 3 ) and country ( 2 and 4$)$ levels. ${ }^{* * *} \mathrm{p}<0.01,{ }^{* *} \mathrm{p}<0.05,{ }^{*} \mathrm{p}<0.1$

One potential problem with our use of $d$-score to explain firm level changes is that industries may have a particular level of division of labor for technological or historical reasons. Our measure will capture these differences but will be unable to indicate whether a country's higher $d$-score is a function of a different organizational structure within industries or whether industries which require greater divisions of labor arise (or strategically situate themselves) in particular countries. To account for this possibility we adjust the $d$-score by an industry mean, producing diffd. Diffd is thus a measure of how a domestic industry's $d$-score differs from the industry mean within our sample. ${ }^{12}$ Columns 3 and 4 demonstrate a positive and significant result between trust and diffd as well, suggesting that industries have greater than

\footnotetext{
${ }^{12}$ For instance, if an industry is situated primarily in countries with increasing trust, these changes in trust will produce more division of labor and will raise the industry d-score. Diffd accounts for this by observing the change relative to the industry mean.
} 
expected division of labor within countries with higher trust. Figure A.1 in the Appendix displays a similar graph to Figure 1, but showing diffd instead of $d$.

In sum, we observe that trust is positively and significantly associated with the division of labor within the ESS dataset. This finding is not simply due to time-invariant country and country-industry factors. Furthermore, it is not merely the case that industries which require high division of labor are selecting into high-trust countries. Prominent research on trust and organizations treats the level of trust within a region as being primarily determined by historical particulars and thus "largely exogenous" with respect to the organization of firms (Bloom et al. 2012a). Trust has been found to depend on weather conditions (Durante 2010), past literacy rates and institutions (Tabellini 2008) and "crucial events in citystates during the medieval period and earlier" (Guiso et al, 2008; all cited in Bloom 2012a). Nevertheless, we are sensitive to the possibility of reverse causation given our sample and we prefer to present the results as correlational. Nevertheless we believe that the findings are suggestive and point to external validity for our experiment demonstrating a causal effect of trust on division of labor.

\section{Conceptual Considerations}

Having shown suggestive correlations between trust and the division of labor at the country level, we now discuss the concepts, as well as the intuition behind a causal connection, in more detail. The division of labor can broken down into "task division", referring to the decomposition of a task into subtasks, and "task allocation" which is the actual assignment of these subtasks to individuals. Our study focuses on task allocation, using job titles as a proxy for allocated task in Section 2, and directly observing choices over tasks in Section 4.

Trust is a notoriously hard concept to define, but within the existing definitions there appears to be a convergence on the role of belief as an important element. Diego Gambetta (2000) summarizes an interdisciplinary consensus as follows: trust is the "subjective probability with which an agent assesses that another agent or group of agents will perform a particular action, both before he can monitor such action and in a context in which it affects his own action." ${ }^{13}$ Psychologists have also made an important

\footnotetext{
${ }^{13}$ Another popular definition of trust is that a trusting act is one which increases one's exposure to both positive and negative externalities as a result of another party's decision (Kreps 1990). This definition is compatible with our model and experiment, as the trusting choice has the highest possible positive and negative externalities.
} 
distinction between the "benevolence" component of trust and the "competence" component (Rotter 1971). ${ }^{14}$

We define trust as a belief in another selecting an efficient action. We believe, following Camerer \& Knez (1996), that this definition is appropriate to the context of a firm. Fehr (2009) observes that the belief component of trust can have lasting effects "only... as an equilibrium selection device". This is the case in our experiment (and the model in the appendix), since the selection of generalist or specialist equilibria is a function of trust. Sapienza et al. (2013) note that the "trust in strangers" survey question is most relevant to beliefs within a laboratory, rather than preferences. McEvily et al. (2012) finds that, when the "target of trust" is fully a stranger, attitudinal measures of "trust in strangers"-like the World Values Survey Trust question — do correlate with trusting behavior in a controlled environment. ${ }^{15}$ By focusing attention on trust in an anonymous interaction in a productive context, our model (and experiment) remains relevant to the "trust in strangers" measure of trust that we use in section 2.

The idea that levels of trust affect division of labor rests on the observation that the division of labor requires a level of vulnerability; if I choose to specialize then I often limit my ability to observe what others are doing in complementary tasks, as well as hindering my ability to substitute for them. ${ }^{16}$ Michael Skapinker of the Financial Times notes that, "There is no point in hiring people with specialist knowledge if you are going to monitor their every move. That is where trust comes in." (Covey, 2006 p. 292) Due to the reliance on the other person's performance and the related vulnerability we argue that trust plays a role in a group's willingness to specialize and ability to sustain specialization.

To clarify our argument and provide a conceptual sketch of the experimental game we describe in the subsequent section one can think about situation in which two workers, specialized in distinct but complementary skills can choose to specialize, generalize or take the outside option (Appendix IV present a simple game theoretic model of this scenario which is adapted from the productive set-up in Becker \& Murphy's (1992) classic theoretical work on the division of labor). Just as in the examples in the introduction, the vulnerability of specialization is the result of a subject being hurt by the under-provision of effort in a complementary task. Subjects can reduce this vulnerability by generalizing which—while

\footnotetext{
${ }^{14}$ While both dimensions of trust are likely relevant to determining the division of labor, our empirical contributions are mostly related to the benevolence dimension. Our measure of trust (in Section 2) is correlated with behavioral measures in the lab and field which do not appear to be competence-driven, such giving in the trust-game, and leaving one's doors unlocked.

${ }^{15}$ McEvily et al. (2012) also mention the important of altruism and risk-seeking as possible confounds in the standard "trust game" of Berg et al. (1995).

${ }^{16}$ Importantly, changing tasks incurs switching costs and/or specialization involves some level of "learning by doing" (Arrow 1962) such that learning one skill incurs an opportunity cost of other complementary skills not learned.
} 
sacrificing efficiency—ensures a minimal level of effort across tasks. ${ }^{17}$ Subjects can also not work at all which reduces their vulnerability ${ }^{18}$ completely. Their choices are then shown to reflect their beliefs in another's action, with uncertainty resulting in generalist productive form. Increasing the belief in the efficient action results in specialization.

\section{Experimental Design}

To test whether the level of trust in an organization causally affects division of labor, we need (1) a task that measures the extent of specialization and (2) a way to randomly assign individuals/teams into high or low trust environments. We will describe the operationalization of our experiment in turn. Full instructions were available for participants to read and were read aloud prior to the experiment. These instructions are presented in Appendix I.

\subsection{Task}

We sought to devise an experimental game that could approximate the feeling of an actual work environment. We thus engage subjects in a real-effort task in continuous time. Our design attempts to capture the process of specialization we describe in our introduction as occurring between coauthors of a paper. This would seem to require distinct complementary subtasks, like sections of a paper. However, because the division of labor can be driven by heterogenous skills among a group, as well as beliefs about such skills, it was important to use a design in which individuals have similar levels of potential productivity while allowing for different levels of actual productivity within the game. We did not want individuals switching to a different task simply because they thought they would be more skilled at it. To avoid these pitfalls, our design uses the same task and then creates specialization by imposing costs of switching. ${ }^{19}$

The task is to "de-mine" a field via simple clicking, with a 9 second enforced delay between clicks using a 20x20 grid (see Figure 2 for a screenshot). We expect that all students should have a similar proficiency in clicking.

\footnotetext{
${ }^{17}$ Just as - in the specialized coauthors example from earlier-taking time to construct a literature review detracts from the time spent doing the model, but does ensure progress in both complementary tasks.

${ }^{18}$ Vulnerability here means their exposure to negative externalities as a result of another's choice. Not working (taking the outside option in the model) can provide the highest minimum possible payoff regardless of the strategic choice of another because you are not expending costly effort.

${ }^{19}$ Switching mirrors productivity losses from "switching costs", classically considered a component of the gains to specialization (Smith 2005).
} 


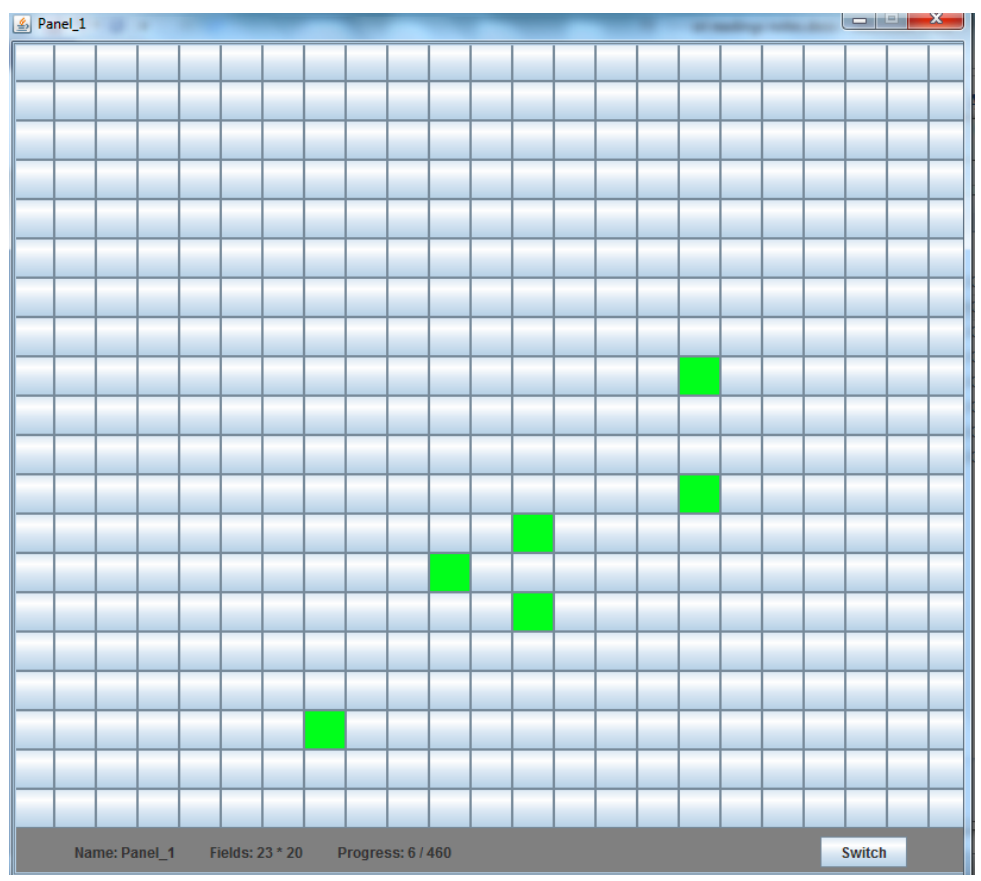

FIGURE 2. "DE-MINING” TASK

Holding the actual tasks constant, we then "specialize" the participants by dividing the field up into thirds, with each individual only able to work in one-third of the field at a time. Each individual has a specialized unique third of the field, and the game begins with them viewing this portion of the field. To engage in work a non-specialist portion of the field an individual must click "switch" and pay a switching cost equivalent to 18 seconds of effort. Upon clicking the switch button (observable in the bottom right corner of Figure 2), subjects are presented with a switching screen (see Figure 3 for a screenshot). In this screen they can observe the progress of made in the other subfields and choose to switch and then work in them. ${ }^{20}$

\footnotetext{
${ }^{20}$ Subjects must pay the switching cost before observing this screen.
} 


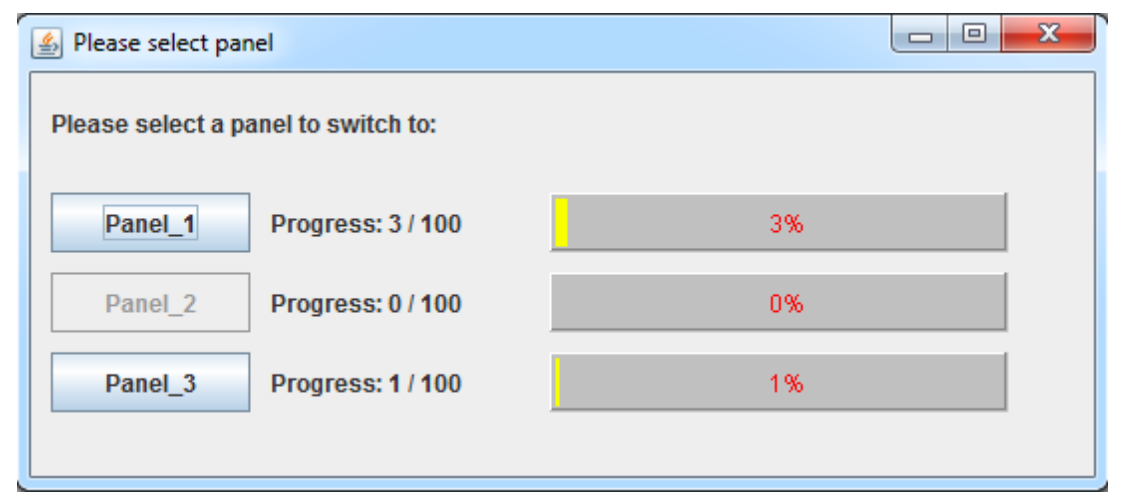

FIGURE 3. SWITCHING SCREEN

Subjects in our experiment were also permitted to browse the internet during the experiment, acting as the outside option and the 9 second delay served to make the option more enticing (as one could potentially multitask, with perhaps some cost to productivity). A browser window displaying Google.com was open on their desktop at the time of the experiment and, informally, we observed about half of the participants using the internet.

In each of 2 experimental rounds, participants had 13 minutes time to work on their subfield and/or switch to another subfield and work there. Thus if every individual fully specialized the maximum production within a subfield would be 13 minutes times 60 seconds divided by 9 seconds waiting time per click, or 86. An individual in group $j$ 's payoff is determined by

$$
\$ 5+\frac{\$ 20 * \min \left(\sum_{i} y_{i j 1}\right)+\$ 20 * \min \left(\sum_{i} y_{i j 2}\right)}{3 * 86}
$$

This payoff includes a $\$ 5$ show-up fee plus $\$ 20$ times the minimum production y within a subfield $i$ in both round 1 and round 2 . These round-specific payoffs are then split evenly among the group (there are 3 people per group and thus they are divided by 3) as well as normalized by the maximum possible production (divided by 86). Thus the maximum payoff within this game is just over $\$ 18$ for each individual. The payoff function makes the game resemble a minimum effort coordination game (Van Huyck et al 1990; Knez \& Camerer 1994; Weber 2006).

After Period 1, i.e. the first 13 minutes, subjects were given information on the performance of their group. Subjects observed their group production for the round-- $\min \left(\sum_{i} y_{i j 1}\right)$--and were reminded of the maximum number of clicks (86) for context. They then repeated the task again in period 2.

To return once more to our example of specialization among co-authors, our task models a situation in which each author has a specialized section of the paper to work on, and everyone is better off if everyone works on their specialized section. However, each author also has the opportunity and ability to 
switch to another's task at a cost (we can see this as the cost of reorienting, or the cost of learning), observe the quality of that task, ${ }^{21}$ and then begin contributing to it. Rather than observe an ex ante agreement to divide labor then, this task enables us to observe the actual task selection of the group members and thus the actual extent to which they specialize.

\subsection{Trust Manipulation}

In order to create a 'high trust' and a 'low trust' environment, we use a method that is similar to the one proposed by Bartling et al. (2013). We prime the trust of individuals by presenting them with actual examples of past performance in this task, taken from a pilot study. We present this information neutrally, following the instructions, describing it as "an actual example of a subject's performance in a game played previously". ${ }^{22}$ While the text is the same for all subjects, the examples are different. The primes are included below in Figure 4: Panel A for 'Low Trust' treatment and Panel B for 'High Trust' treatment. Note that these primes do not specify the reason for the difference in clicks, and thus (using the terminology in Rotter, 1971 and elsewhere) it could be a "competency" difference or it could be a "benevolence" difference. Loosely speaking, the former would be the case if the subject failed to click quickly while the latter would be the case if the subject abstained from clicking in order to browse the internet.
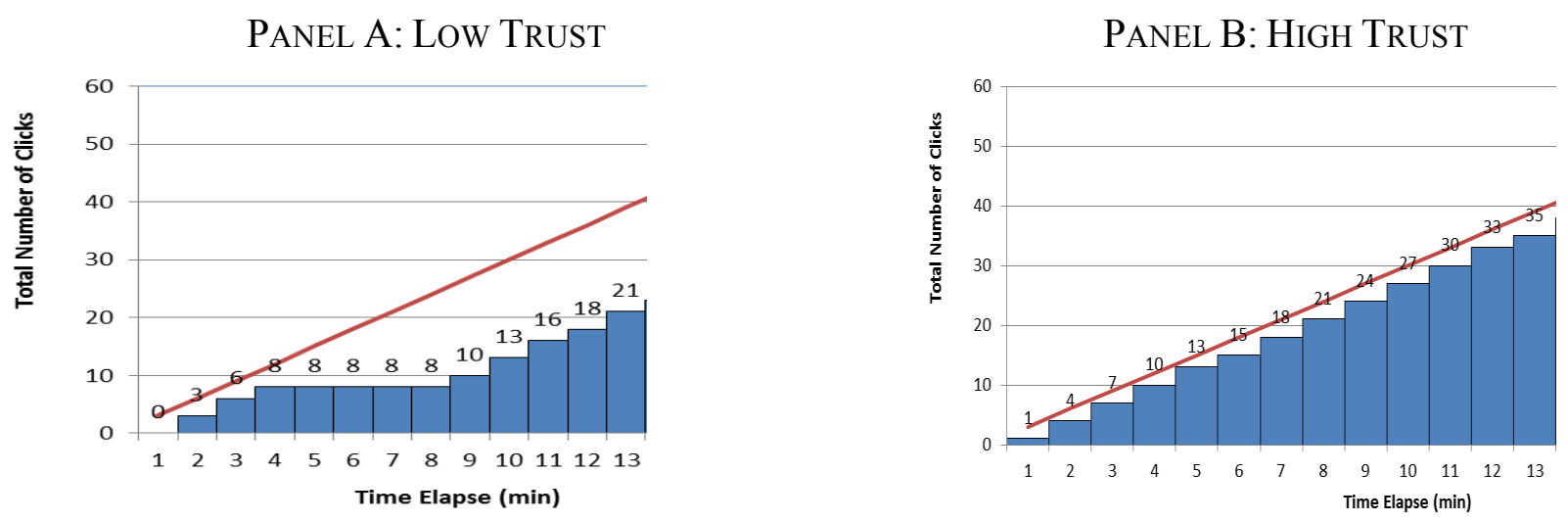

Figure 4. TRUST MANIPULATION

We use these trust prime to manipulate the level of trust among study participants. Subjects were told that "The Red Line shows the total number of clicks possible" and "The Blue Bars show the actual

\footnotetext{
${ }^{21}$ We thus assume that specialization imposes a positive cost of observing another's progress for the same reasons: a mental or physical reorienting cost, and/or a cost of, for instance, learning enough about the relevant literature that one can assess how good the literature review is and how it can be improved.

${ }^{22}$ It was made clear to the participants beforehand that the experiment would involve no deception.
} 
(cumulative) number of clicks. ${ }^{, 23}$ In the post-experimental survey, we asked subjects to recall how trustworthy they believed their team was (on a scale of 1-7) "as they began the task" and "at the end of the task." This survey was voluntary and there was some observed attrition (10 of the 63 subjects did not complete the survey) which reduces our number of observations somewhat. But the subjects for which we have a measure, we find a significant difference in how trustworthy they thought their team was at the end of the experiment, as well as how likely they were to experience a decline in trust. Subjects in the "Low Trust" condition are significantly more likely $(\mathrm{p}<.05)^{24}$ to report a lower "trustworthy" rating after the experiment than those in the "High Trust" condition. Subjects in "Low Trust" were also significantly more likely to exhibit an overall decrease in trust ("trust after" minus "trust before"), and the mean change in trust was negative in low trust groups (-.285).

\subsection{Procedure}

We conducted the experiment at the Columbia Experimental Laboratory for the Social Sciences (CELSS), using 63 Columbia University undergraduates who were recruited via ORSEE (Greiner, 2004). There were 3 sessions lasting approximately 45 minutes apiece. A show up fee of $\$ 5$ combined with the incentivized earnings produced an average payoff of $\$ 15$ per subject. Participants were unaware of the nature of the experiment before entering the laboratory.

\section{Experimental Results}

In the following, we treat the number of task switches as examples of generalist behavior and we measure the effect of trust on generalist behavior on the intensive and extensive margins. We define a task switch as occurring when one subject switches to another's field and then proceeds to click one or more times on this non-specialized field, switching back to the specialized task is costless and not counted as a task switch. ${ }^{25}$ Monitoring switches - in which one switches to another field but then (costlessly) switches back without working-were possible in this game but somewhat uncommon. Of the 131 acts of switching we observe, only $14(10.6 \%)$ were monitoring switches. We test whether there is a significant effect of trust on a pure monitoring switch, and the results are insignificant $(\mathrm{p}=.86)$ with a coefficient of .01 . While the inclusion of these monitoring switches does not substantively impact our results (see Appendix V), we

\footnotetext{
${ }^{23}$ The data was taken from a pilot experiment using the same game, but in which there was a longer delay imposed between clicks and thus the maximum was lower than 86 .

${ }^{24}$ All reported p values are from OLS regressions clustered at the group level unless otherwise noted.

${ }^{25}$ And all "switching back" behavior would be preceded by an initial switch which would strengthen our results.
} 
exclude them for our main analysis and focus on task switching, in which subjects actually work on nonspecialized tasks.

Figure 5 presents the number of switches in a cumulative distribution function for both treatments. The figure shows clearly the difference between the treatments in specialized behavior. In the 'High Trust' treatment, $66 \%$ of the participants fully specialize, i.e. they never switched to another field. In stark contrast, only $28 \%$ percent of participants in the 'Low Trust' treatment never switched, i.e. fully specialized on their field. The figure shows not only that there are differences on the extensive margin but also that the number of switches are higher in the 'Low Trust' treatment (on average, subjects in this treatment switched .92 times) compared to the 'High Trust' treatment (.5 switches).

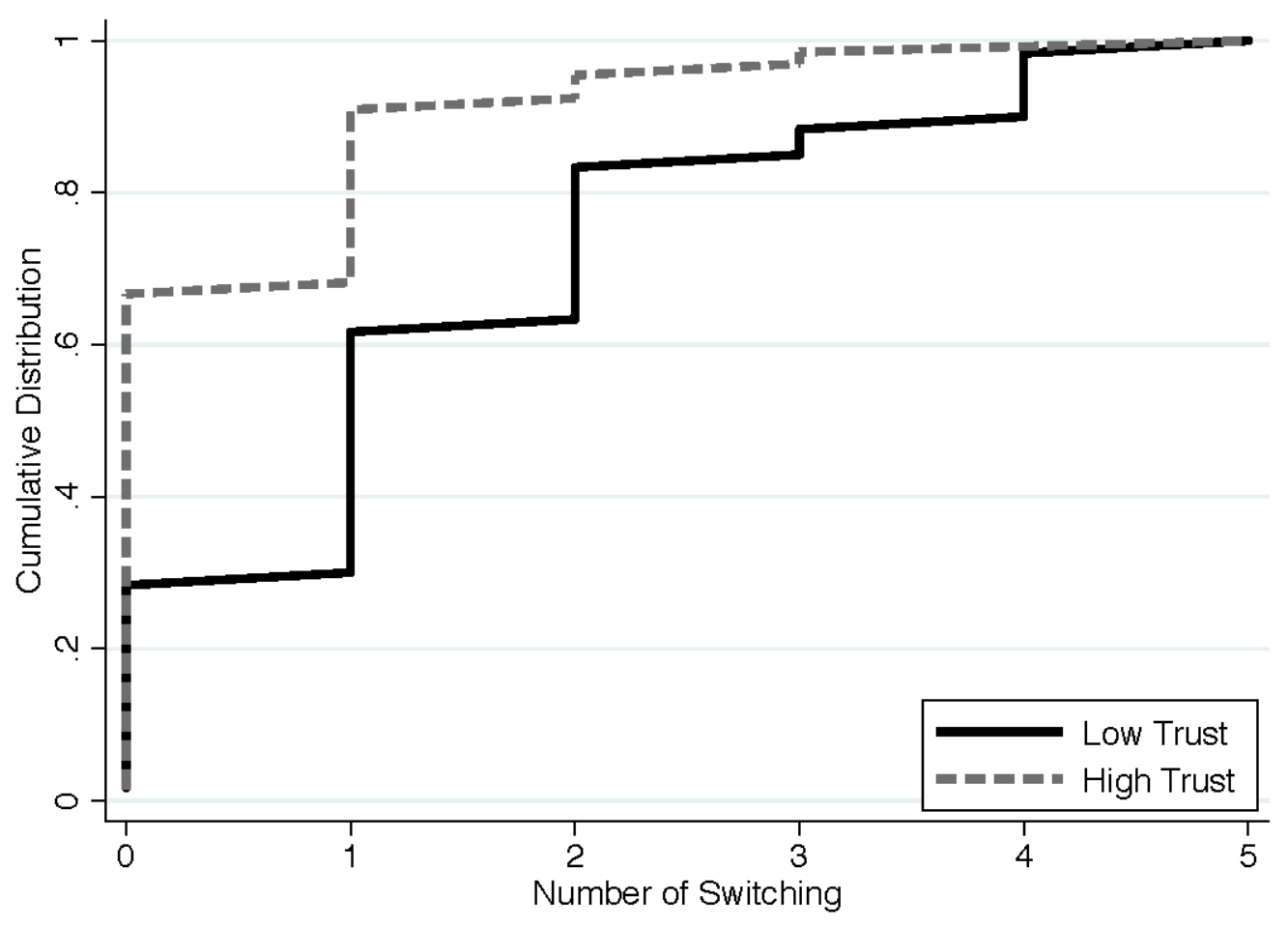

FIGURE 5. A CDF REPRESENTATION OF SPECIALIST BEHAVIOR BY TRUST CONDITION

While Figure 5 pools our observations across both periods, Figure 6 shows the trend in specialist behavior across periods. While we observe positive trends in specialization across both conditions, the increase in specialist behavior is only significantly different in the 'High Trust' treatment. Using a logit regression on specialization and clustering at the group level, the high trust groups demonstrably improve from Period 1 to Period $2(p<.05)$, while the change for the low trust groups is not significant $(p=.26)$. The differences between the two treatments in the time trend is, however, not significant on any conventional 
level. But the point estimate indicates that the difference in division of labor in the two environments intensifies over time.

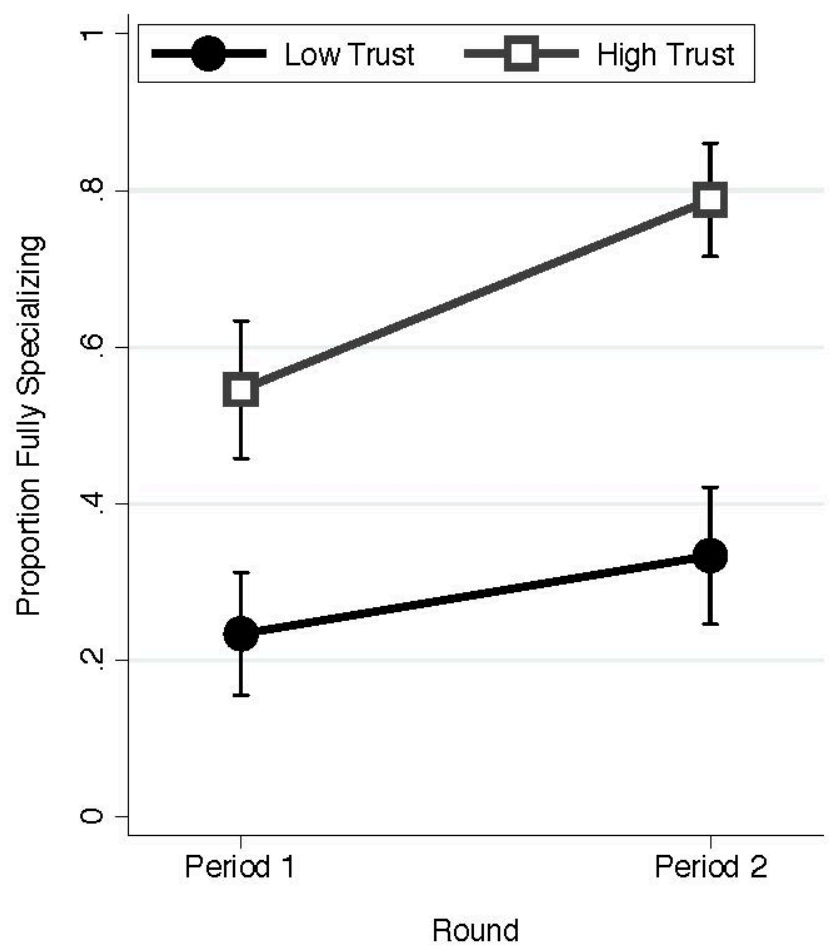

FiguRE 6. SPECIALIST BEHAVIOR OVER TIME

Table 2 shows the results of the Figure 5 and Figure 6 in a regression framework in which the dependent variable in model (1) is a dummy variable that is 1 if a participants fully specialized, i.e. never switches, and 0 otherwise. In model (2), the dependent variable is a count measure on the number of switches. Standard errors are clustered on the group level.

The table confirms the results from the figures: The 'High Trust' treatment increases the probability of fully specializing behavior by 34.3 percent $(p<0.05)$. The 'High Trust' treatment also decreases the number of switches (Model 2). Participants in the 'High Trust' treatment switch 1.036 times less than participants in the 'Low Trust' treatment. The coefficients on 'Round' show that for participants in the 'Low Trust' treatment, the incidence of fully specializing increases somewhat but this increase is not statistically significant $(p=.25)$. The interaction 'High Trust $\mathrm{x}$ Round' indicates that for the 'High Trust' treatment specialized behavior increase further $(p=.327)$. While the difference in the time trend between the treatments is not statistically significant, the increase in specialized behavior is statistically significant for the 'High Trust' treatment $(p<.05)$. 
TABLE 2-THE CAUSAL IMPACT OF TRUST ON DIVISION OF LABOR

\begin{tabular}{|c|c|c|}
\hline Dependent Variable & $\begin{array}{l}(1) \\
\text { Specialize Dummy }\end{array}$ & $\begin{array}{l}(2) \\
\# \text { of Switches }\end{array}$ \\
\hline High Trust $(=1)$ & $\begin{array}{l}1.372 * * \\
(0.623) \\
{[.343]}\end{array}$ & $\begin{array}{l}-1.036 * * \\
(0.473)\end{array}$ \\
\hline Round & $\begin{array}{l}0.496 \\
(0.434) \\
{[.124]}\end{array}$ & $\begin{array}{l}-0.667 * * \\
(0.293)\end{array}$ \\
\hline High Trust $\times$ Round & $\begin{array}{l}0.633 \\
(0.646) \\
{[.158]}\end{array}$ & $\begin{array}{l}0.273 \\
(0.331)\end{array}$ \\
\hline Constant & $\begin{array}{l}-1.190 * * \\
(0.472)\end{array}$ & $\begin{array}{l}1.733 * * * \\
(0.381)\end{array}$ \\
\hline $\begin{array}{l}\text { R-squared } \\
\mathrm{N}\end{array}$ & 126 & $\begin{array}{l}0.190 \\
126\end{array}$ \\
\hline
\end{tabular}

Note: Results from a logit (1) and an OLS (2) regression, robust errors clustered at the group level and reported in parentheses. Marginal effects reported in brackets. $* * * \mathrm{p}<0.01, * * \mathrm{p}<0.05,{ }^{*} \mathrm{p}<0.1$

The results so far show that creating a high trust environment endogenously leads to more specialization and less switching tasks. One possible explanation for increased specialized behavior in the high trust groups is that the high trust manipulation might have induced more effort, perhaps because the prime functions as an anchor. Specializing could then seem to be a response to (expected) high effort. ${ }^{26}$ However, our prime does not specify that the clicks were made in a specialist field, and thus it is not trivial that specializing would be a best response based on an expected "high effort" anchor. ${ }^{27}$ Figure 7 plots effort levels in the two treatment for the two periods together. There are no significant differences in effort overall $(p=.13)$. Splitting the sample by round, round 1 effort is higher in the 'High Trust' treatment compared to the 'Low Trust' treatment $(p<.05)$, and there is no difference in effort in round 2.

\footnotetext{
${ }^{26}$ Because our task uses timed clicking as effort, we consider all clicks which require a 9 second delay in our calculation of effort expended by subjects. Thus we see clicks in an individual's specialized field and nonspecialized fields as effort.

${ }^{27}$ Moreover, given the way we define trust, the explanation that switching behavior is due to an increased belief in "anchored" specialist effort is compatible with our theory as well.
} 
In sum, the experimental evidence shows that exogenously changed trust levels affect how specialized members of a group work together. In a high trust environment, we observe more division of labor, i.e. individuals work on their specialized task and do not switch as often to the task of others. As a result, they also earn more. Payoffs are $\$ 15.10$ in 'High Trust' groups versus 14.56 in 'Low Cost' groups $(p<.01)$. Trust makes groups more specialized and more productive, with level of specialization seem to increase over time. The experimental approach allows us to provide internally valid effects of our manipulation (trust) on our outcome measure (division of labor), which complements the results from the cross-country analysis (section 2).

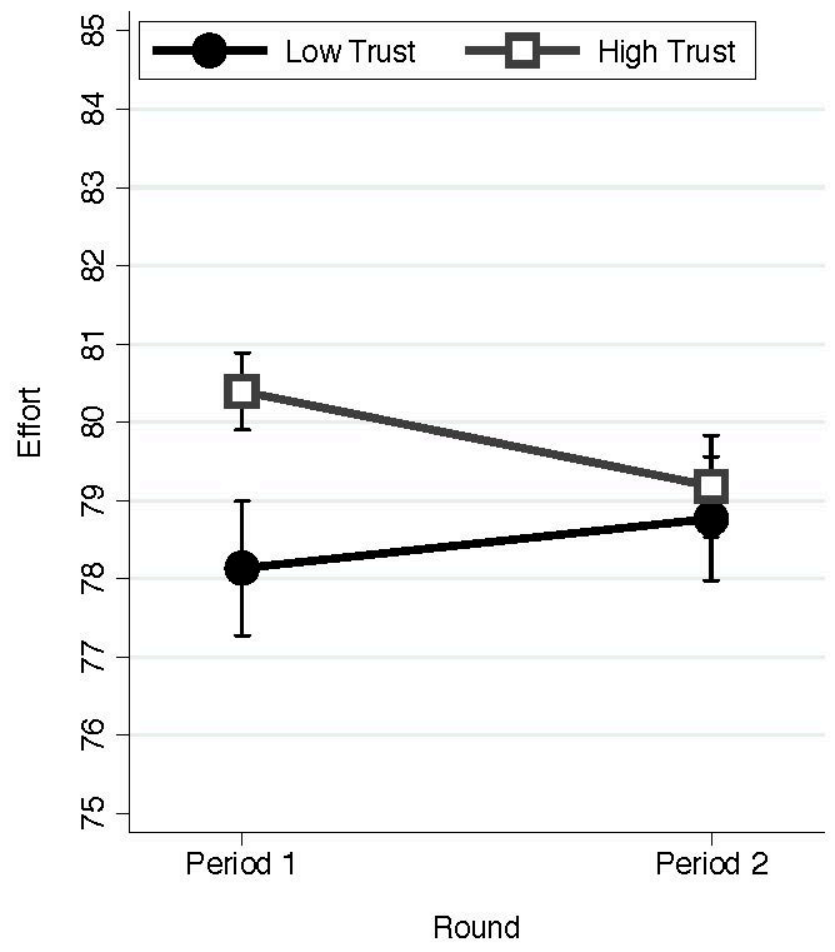

FIGURE 7. EFFORT ACROSS PERIODS AND TREATMENTS

\section{Conclusion}

This paper investigates whether differences in corporate culture can explain the emergence of different organizational structure, especially different degrees of division of labor. We begin our study with evidence on the cross-country correlation between trust and the division of labor. But beyond this motivating example, we adopt the perspective of micro-structural analysis of organizational form 
(Puranam, 2014) in which the firm is viewed as a collection of smaller productive structures that are embedded in a larger framework. We model and experimentally evaluate an organizational microstructure that can attain different levels of productivity depending on its level of division of labor. We are then able to provide causal evidence on the question of trust and division of labor by showing in an experiment that exogenously 'shocking' an 'organization' with 'high' or 'low' trust levels leads to the emergence of different degrees of division of labor. This evidence suggests that one aspect of corporate culture-trustcan have an effect on corporate performance through organizational structure. Demonstrating that trust affects organizational structure is important both because it sheds light on the nature of firms - an age-old puzzle in economics and strategy - and also because it represents a plausible mechanism which could drive the relationship between trust and economic growth.

While the experimental evidence provides high internal validity, the cross-country evidence is high on external validity. Taken together, these two pieces of empirical evidence provide a solid foundation to study further the effect of trust on division of labor.

While demonstrating the causal impact of trust on specialization, this paper raises several important questions and points to areas where further research is needed. Of major interest is how easy it is to change an existing culture of trust, since levels of trust can have long-lasting effects on organizations. To that end it would be useful to document how start-ups confront this problem by establishing strong cultures. Additional field evidence in this vein would be of significant value. There is also the matter of trust as only one component of corporate culture, but of course culture extends far beyond this and it thought to determine orientations toward innovation, fairness, experimentation and more (O'Reilly et al. 1991). Finally, it could be very useful to analyze the effect of trust on the span of control, including task division as well as task allocation. The relationships among organizational form and these other aspects of culture should prove to be a fruitful avenue of exploration. 


\section{References}

Akerlof, G. A. (1982). Labor contracts as partial gift exchange. The Quarterly Journal of Economics, 543-569.

Alchian, A. A., \& Demsetz, H. (1972). Production, information costs, and economic organization. The American Economic Review, 62(5), 777-795.

Algan, Y., \& Cahuc, P. (2010). Inherited trust and growth. The American Economic Review, 100(5), 2060-2092.

Almazan, A., \& Molina, C. A. (2005). Intra-industry capital structure dispersion. Journal of Economics \& Management Strategy, 14(2), 263-297.

Arrow, K. J. (1962). The economic implications of learning by doing. The Review of Economic Studies, 29(3), 155-173.

Baker, G., Gibbons, R., \& Murphy, K. J. (1994). Subjective performance measures in optimal incentive contracts. The Quarterly Journal of Economics, 109(4), 1125-1156.

Bartling, B., Fehr, E., \& Huffman, D. (2013). Institutions and the causal effect of trust. Working Paper.

Becker, G. S., \& Murphy, K. M. (1994). The division of labor, coordination costs, and knowledge. In Human Capital: A Theoretical and Empirical Analysis with Special Reference to Education (3rd Edition) (pp. 299-322). The University of Chicago Press.

Berg, J., Dickhaut, J., \& McCabe, K. (1995). Trust, reciprocity, and social history. Games and Economic Behavior, 10(1), 122-142.

Bloom, N., Genakos, C., Sadun, R., \& Van Reenen, J. (2012a). Management practices across firms and countries. The Academy of Management Perspectives, 26(1), 12-33.

Bloom, N., Sadun, R., \& Van Reenen, J. (2012b). The organization of firms across countries. The Quarterly Journal of Economics, 127(4), 1663-1705.

Bohnet, I., Greig, F., Herrmann, B., \& Zeckhauser, R. (2008). Betrayal aversion: Evidence from Brazil, China, Oman, Switzerland, Turkey, and the United States. The American Economic Review, 98(1), 294-310.

Camerer, C., \& Knez, M. (1996). Coordination, organizational boundaries and fads in business practices. Industrial and Corporate Change, 5(1), 89-112.

Camerer, C., \& Weber, R. (2013). Experimental organizational economics. The Handbook of Organizational Economics, 213. 
Chandler, A. D. (1962). Strategy and structure: Chapters in the history of the american enterprise. Massachusetts Institute of Technology Cambridge.

Chatterji, A., Findlay ,M., Jensen, N., Meier, S., \& Nielson, D., (2014) "Field Experiments in Strategy". Working Paper, Columbia University.

Covey, S. M. (2006). The speed of trust: The one thing that changes everything. Simon and Schuster.

Crockett, S., Smith, V. L., \& Wilson, B. J. (2009). Exchange and Specialisation as a Discovery Process*. The Economic Journal, 119(539), 1162-1188.

Croson, R., Anand, J., \& Agarwal, R. (2007). Using experiments in corporate strategy research. European Management Review, 4(3), 173-181.

Durante, R. (2010). Risk, Cooperation and the Economic origins of social Trust: an empirical Investigation. Sciences Po.

Falk, A., \& Zehnder, C. (2013). A City-Wide Experiment on Trust Discrimination. Journal of Public Economics, 100, 15-27.

Feenstra, R., Inklaar, R., \& Timmer, M. (2013). The Next Generation of the Penn World Table. Available for download at www.ggdc.net/pwt

Fehr, E., Kirchsteiger, G., \& Riedl, A. (1998). Gift exchange and reciprocity in competitive experimental markets. European Economic Review, 42(1), 1-34.

Fehr, E., \& List, J. A. (2004). The hidden costs and returns of incentives-trust and trustworthiness among CEOs. Journal of the European Economic Association, 2(5), 743-771.

Fehr, E. (2009). On the economics and biology of trust. Journal of the European Economic Association, 7(2-3), 235-266.

Fershtman, C., \& Gneezy, U. (2001). Discrimination in a segmented society: An experimental approach. The Quarterly Journal of Economics, 116(1), 351-377.

Gambetta, D. (2000). Can we trust trust? In D. Gambetta (Ed.) Trust: Making and breaking cooperative relations (pp. 213-237). Oxford, UK: University of Oxford.

Glaeser, E. L., Laibson, D. I., Scheinkman, J. A., \& Soutter, C. L. (2000). Measuring trust. The Quarterly Journal of Economics, 115(3), 811-846.

Goyal, S., \& Janssen, M. C. (1997). Non-exclusive conventions and social coordination. Journal of Economic Theory, 77(1), 34-57. 
Guiso, L., Sapienza, P., \& Zingales, L. (2008). Long term persistence (No. w14278). National Bureau of Economic Research.

Greiner, B. (2004). An online recruitment system for economic experiments. Forschung und wissenschaftliches Rechnen 2003. GWDG Bericht 63, Göttingen : Ges. für Wiss.

Datenverarbeitung, 79-93.

Gulati, R., \& Nickerson, J. A. (2008). Interorganizational trust, governance choice, and exchange performance. Organization Science, 19(5), 688-708.

Kimbrough, E. O., Smith, V. L., \& Wilson, B. J. (2008). Historical property rights, sociality, and the emergence of impersonal exchange in long-distance trade. The American Economic Review, 1009-1039.

Kimbrough, E. O., Smith, V. L., \& Wilson, B. J. (2010). Exchange, theft, and the social formation of property. Journal of Economic Behavior \& Organization, 74(3), 206-229.

Knack, S., \& Keefer, P. (1997). Does social capital have an economic payoff? A cross-country investigation. The Quarterly Journal of Economics, 112(4), 1251-1288.

Knez, M., \& Camerer, C. (1994). Creating expectational assets in the laboratory: Coordination in 'weakest-link' games. Strategic Management Journal, 15(S1), 101-119.

Kogut, B., \& Zander, U. (1996). What firms do? Coordination, identity, and learning. Organization science, 7(5), 502-518.

Kreps, D. M. (1990). Corporate culture and economic theory. In J. E. Alt \& K. A. Shepsle (Eds.), Perspectives on positive political economy (pp. 109-110). Cambridge, England: Cambridge University Press.

Lawrence, P. R., \& Lorsch, J. W. (1967). Differentiation and integration in complex organizations. Administrative Science Quarterly, 1-47.

McEvily, B., Radzevick, J. R., \& Weber, R. A. (2012). Whom do you distrust and how much does it cost? An experiment on the measurement of trust. Games and Economic Behavior, 74(1), 285-298.

Meier, S., Pierce, L., \& Vaccaro, A. (2014). "Trust and In-Group Favoritism in a Culture of Crime." IZA Discussion Paper No. 8169, Institute for the Study of Labor. Available at SSRN: http://ssrn.com/abstract $=2441465$

Nelson, R. R. (1991). Why do firms differ, and how does it matter? Strategic Management Journal, 12(S2), 61-74.

Nickerson, J. A., \& Zenger, T. R. (2008). Envy, comparison costs, and the economic theory of the firm. Strategic Management Journal, 29(13), 1429-1449. 
O'Reilly, C. A., Chatman, J., \& Caldwell, D. F. (1991). People and organizational culture: A profile comparison approach to assessing person-organization fit. Academy of management journal, 34(3), 487-516.

Palan, N. (2010). Measurement of specialization-The choice of indices. Research Centre International Economics, FIW Working Papers No. 62. Vienna.

Poppo, L., \& Zenger, T. (2002). Do formal contracts and relational governance function as substitutes or complements?. Strategic management journal, 23(8), 707-725.

Porter, M. E. (1979). The structure within industries and companies' performance. The Review of Economics and Statistics, 61(2), 214-227.

Puranam, P., Alexy, O., \& Reitzig, M. (2013). What's" New" about New Forms of Organizing?. Academy of Management Review, 39 (2), 168-180.

Puranam, P., Powell, B. C., \& Singh, H. (2006). Due diligence failure as a signal detection problem. Strategic Organization, 4(4), 319-348.

Puranam, P., \& Vanneste, B. S. (2009). Trust and governance: Untangling a tangled web. Academy of Management Review, 34(1), 11-31.

Puranam, P. (2014). Designing Collaboration. Unpublished Manuscript.

Raveendran, M., Puranam, P., \& Warglien, M. (2015). Emergence and stability of the division of labor: Experimental evidence. Forthcoming at Management Science.

Rotter, J. B. (1971). Generalized expectancies for interpersonal trust. American psychologist, $26(5), 443$.

Santos, F. M., \& Eisenhardt, K. M. (2005). Organizational boundaries and theories of organization. Organization science, 16(5), 491-508.

Sapienza, P., Toldra-Simats, A., \& Zingales, L. (2013). Understanding trust. The Economic Journal, 123(573), 1313-1332.

Schein, E. H. (2010). Organizational culture and leadership (Vol. 2). John Wiley \& Sons.

Smith, A. (1776). An inquiry into the nature and causes of the wealth of nations. The Electronic Classics Series, J. Manis (Ed.), PSU-Hazleton, Hazleton, PA. Available at: http://www2.hn.psu.edu/faculty/jmanis/adam-smith/wealth-nations.pdf

Sørensen, J. B. (2002). The strength of corporate culture and the reliability of firm performance. Administrative Science Quarterly, 47(1), 70-91. 
Tabellini, G. (2008). Institutions and Culture. Journal of the European Economic Association, 6(2-3), 255-294.

Van Huyck, J. B., Battalio, R. C., \& Beil, R. O. (1990). Tacit coordination games, strategic uncertainty, and coordination failure. The American Economic Review, 80(1), 234-248.

Vanneste, B., Puranam, P., \& Kretschmer, T. (2014). Trust over time in exchange relationships: Meta-analysis and theory. Strategic Management Journal, 35(12), 1891-1902..

Wan, W. P., \& Hoskisson, R. E. (2003). Home country environments, corporate diversification strategies, and firm performance. Academy of Management Journal, 46(1), 27-45.

Weber, R. A. (2006). Managing growth to achieve efficient coordination in large groups. American Economic Review, 96(1), 114-126.

Woodward, J., Dawson, S., \& Wedderburn, D. (1965). Industrial organization: Theory and practice (Vol. 3). London: Oxford University Press. 


\section{Appendix I: Experimental Instructions Instructions for Participants}

Welcome and thank you for participating in our economic decision-making study. If you read and follow these instructions carefully, you can, depending on your decisions and the decisions made by other participants, earn a considerable amount of money. It is therefore important that you take the time to understand the instructions.

IMPORTANTLY: All the information provided here is correct, and all the payments will be made as promised. So there is NO DECEPTION involved. Also, all participants read the exact same instructions for each treatment.

After the experiment your earnings will be paid to you privately, including your show up fee of $\$ 5$ and any additional money you have earned.

\section{Overview of the experiment}

Each and every participant in this experiment is assigned to the same "worker" role. You will be paired with other participants in groups of three to work on a task.

The experiment has 2 periods each lasting 13 minutes. In each period you will be assigned to a group with two others to work on a task. At the outset, participants will be matched randomly.

\section{Details of the experiment}

- In the group of three, each worker will click to de-mine a portion of a larger minefield. The field is divided into thirds: Portion A, Portion B, and Portion C.

- Initially, each worker is placed into a different portion. Workers can choose to work on the same portions of the larger field or different portions.

- Workers de-mine a field by clicking one square in it. After each click there is a 9 second recharge required before another square can be de-mined.

- Participants are free to use the internet as they please during this experiment. Details of your usage will not be tracked by the experimenters.

- After beginning work on one portion of the larger field, a worker can switch to another portion at a cost. 
Screenshot for de-mining:

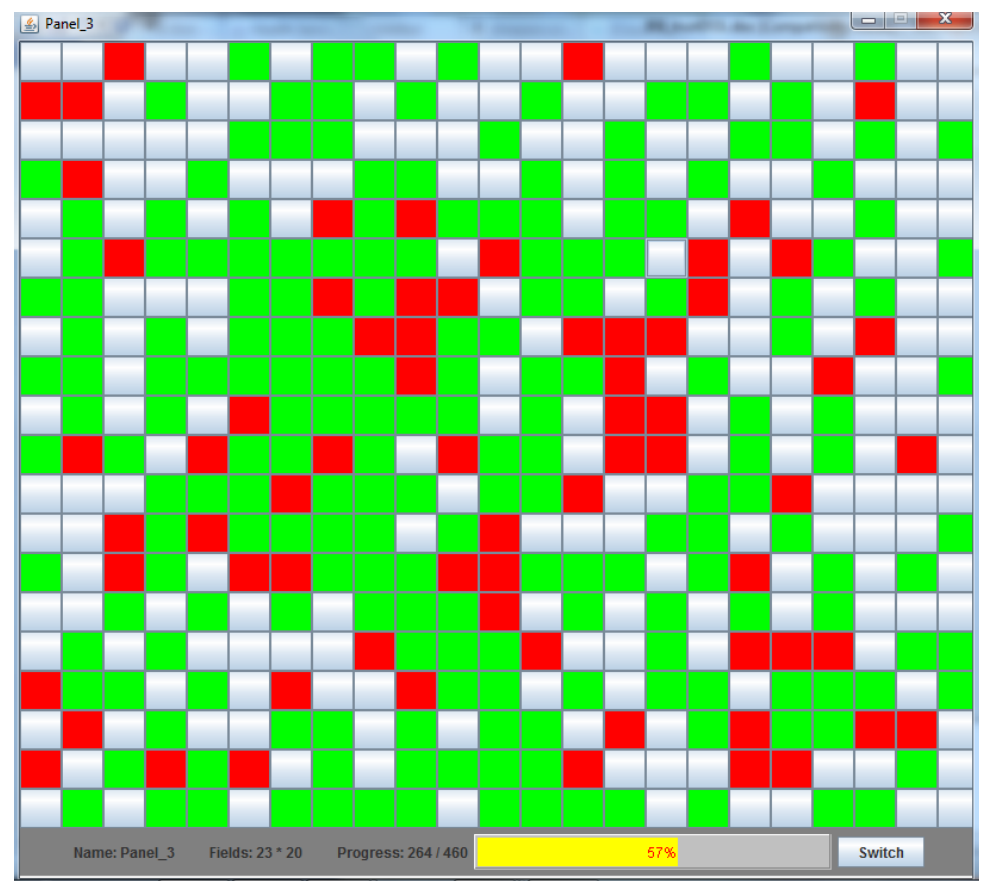

\section{Details of switching}

To switch to a different portion than the one they started in, a worker must pay a cost of 2 clicked squares. So if a worker has 30 squares clicked prior to switching, that player's progress will be reduced to 28 upon the switch. If a worker opts to switch, they will then observe the progress made in each of the other portions of the field and they will be given the opportunity to work on one of those fields if they so choose. At any point during their work on the other field a worker can return to the field they started from without paying a cost by clicking "switch back." Note that the "switch" button incurs a cost while the "switch back" button does not.

Example of a screenshot after switching: 


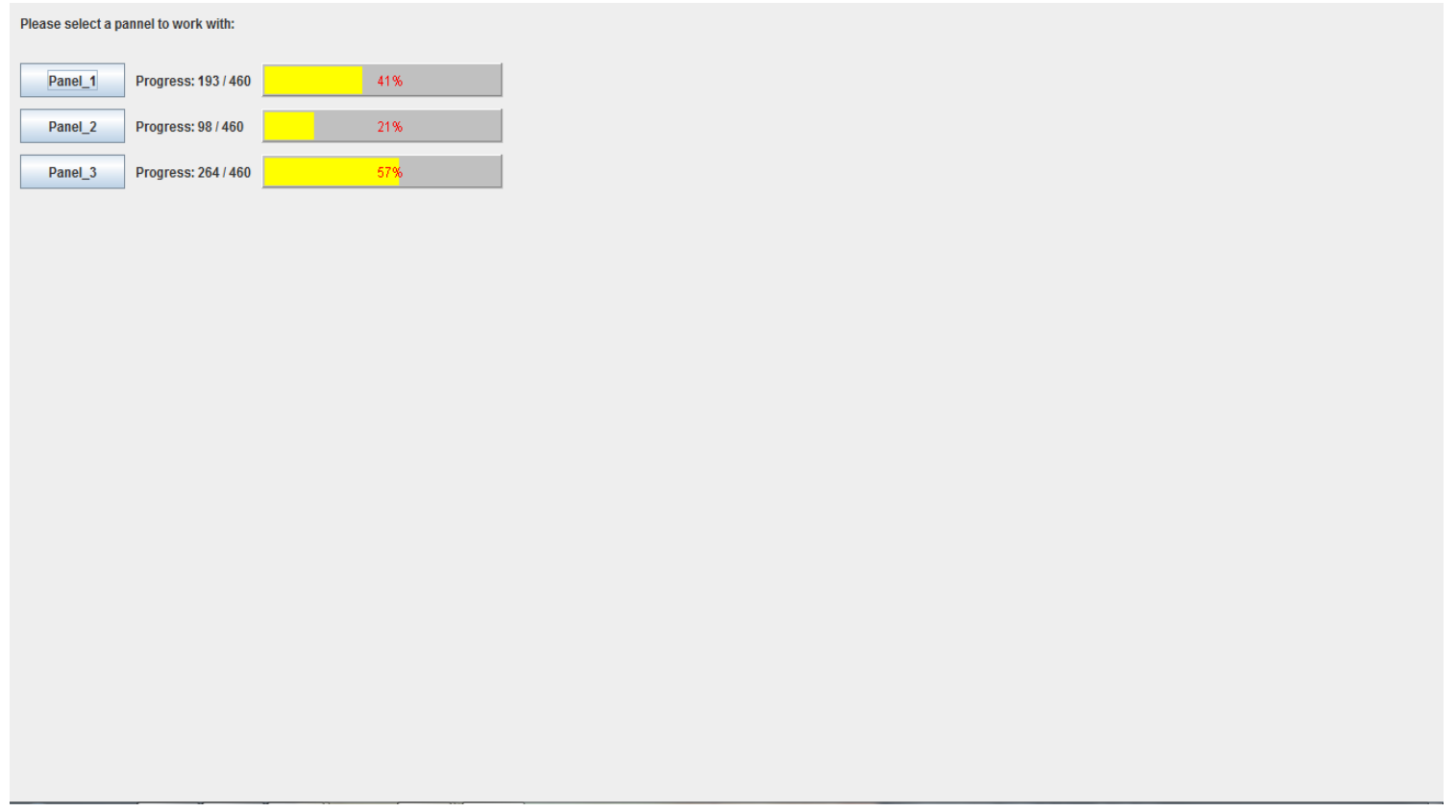

\section{Procedure}

Once a period begins groups are free to begin de-mining fields as they see fit. Each period will last approximately 13 minutes, at which point group and individual payoffs will be computed for that period. Players will be observe to observe their group's output and then the second round will begin, with the rules remaining the exact same as in the first period.

The calculation of payoffs will be as follows: each group will be paid according to the progress made in the least complete portion only. The amount completed in the least-complete portion will be multiplied against $\$ 20$ (the value of a 100\% completed field.) This amount will then be divided equally among the group members.

The experiment consists of two such periods, with payments made for both.

At the end of the experiment, after both periods are over, you will be asked to complete a short survey. After a short time we will call you up to receive your payments. 


\section{Here are some examples:}

* At the end of a period a group has de-mined portions as follows: Portion A 40\% complete, Portion B $40 \%$ complete and Portion C 30\% complete. In this case, the group will receive $\$ 20$ times .30, the amount completed of the least-complete field. Each participant will receive one third of this amount for this period.

* At the end of a period a group has de-mined portions as follows: Portion A $60 \%$ complete, Portion B $50 \%$ complete and Portion C $0 \%$ complete. In this case the group (and each participant) will receive 0 for this period.

* At the end of a period a group has de-mined portions as follows: Portion A 50\% complete, Portion B $50 \%$ complete and Portion C 50\% complete. In this case, the group will receive $\$ 20$ times .50 , the amount completed of the least-complete field(s). Each participant will receive one third of this amount for this period.

Once you have completed reading the instructions please click continue in order to proceed. 


\section{Appendix II: Construction of a measure of the division of labor.}

Existing measures of specialization, such as the Krugman Specialization Index, are suited to analyzing a country's level of industrial specialization. Though there are several of these measures (an overview of which is provided in Palan 2010) they focus on the extent to which an industry dominates the output of a country. Our model offers no clear prediction for a relationship between industrial concentration and trust, thus we constructed a measure based on Gibbs \& Poston $1975^{28}$. The measure $d$ for each industry $j$ is as follows:

$$
d_{j}=1-\frac{\sum_{i=1}^{n} x_{i j}^{2}}{\left(\sum_{i=1}^{n} x_{i j}\right)^{2}}
$$

Where $n$ is the number of possible occupations and $x$ is the number of individuals in that occupation. The matric in Table A.1 (adapted from Gibbs \& Poston) provides some intuition about how this measure changes with the distribution of individuals within occupations and industries.

TABLE A.1-SimULATED INDUSTRY D-SCORES

\begin{tabular}{|c|c|c|c|c|c|c|c|c|}
\hline & $\begin{array}{l}\text { Ind. } \\
1\end{array}$ & $\begin{array}{l}\text { Ind. } \\
2\end{array}$ & $\begin{array}{l}\text { Ind. } \\
3\end{array}$ & $\begin{array}{l}\text { Ind. } \\
4\end{array}$ & $\begin{array}{l}\text { Ind. } \\
5\end{array}$ & $\begin{array}{l}\text { Ind. } \\
6\end{array}$ & $\begin{array}{l}\text { Ind. } \\
7\end{array}$ & $\begin{array}{l}\text { Ind. } \\
8\end{array}$ \\
\hline \multicolumn{9}{|c|}{ occupations } \\
\hline $\mathrm{x}_{\mathrm{i}}$ & 0 & 1 & 20 & 20 & 1 & 1 & 20 & 1 \\
\hline $\mathrm{x}_{\mathrm{j}}$ & 0 & 1 & 5 & 0 & 3 & 0 & 20 & 1 \\
\hline $\mathrm{x}_{\mathrm{k}}$ & 0 & 1 & 0 & 0 & 2 & 1 & 20 & 1 \\
\hline $\mathrm{x}_{1}$ & 0 & 1 & 0 & 0 & 0 & 1 & 20 & 1 \\
\hline $\mathrm{x}_{\mathrm{m}}$ & 200 & 1 & 50 & 20 & 3 & 1 & 20 & 1 \\
\hline $\mathrm{x}_{\mathrm{n}}$ & 0 & 1 & 0 & 20 & 0 & 1 & 20 & 1 \\
\hline $\mathrm{x}_{\mathrm{o}}$ & 0 & 1 & 40 & 0 & 2 & 1 & 20 & 1 \\
\hline$x_{p}$ & 0 & 1 & 60 & 20 & 2 & 1 & 20 & 1 \\
\hline $\mathrm{x}_{\mathrm{q}}$ & 0 & 1 & 0 & 0 & 2 & 1 & 20 & 1 \\
\hline $\mathrm{x}_{\mathrm{r}}$ & 0 & 191 & 25 & 20 & 2 & 1 & 20 & 1 \\
\hline $\mathrm{d}$ & 0 & 0.09 & 0.78 & 0.8 & 0.87 & 0.89 & 0.9 & 0.9 \\
\hline
\end{tabular}

Note: The column vectors denote the number of individuals in particular occupations $x$ within an industry. The bottom row gives the resulting $d$-score for each industry.

\footnotetext{
${ }^{28}$ Smith and Snow (1976) offer a riposte to Gibbs and Poston's proposed measures of division of labor, noting that these measures can be difficult to interpret and do not capture interdependence of roles. We are sympathetic to these criticisms, but we note that interdependence is not an unreasonable assumption for our setting in discussing productive firms. We also observe that Smith and Snow felt that there did not yet exist any truly adequate measure for the "theoretically rich notion" of the division of labor and we are not aware of any strong alternatives.
} 
To further establish the suitability of the $d$ score as measure of the division of labor we consider it in well-established theoretical contexts. A regression of GDP on $d$ provides evidence that the division of labor is, in fact, associated with the wealth of nations. Industries with the highest observed $d$-score include "public administration" (judiciary and police force, etc.) and "specialized construction activities". Industries that receive the lowest $d$-scores include fishing and ore mining. The mean country-industry $d$-score we observe in the sample is .72 with a standard deviation of .24 .

One possible concern about the $d$-score is that low trust countries simply give less precise answers to the occupational question, which would decrease the division of labor score. We cannot rule this out, but these are phone interviews conducted by ESS and the amount of time spent in the interview is not correlated with the level of trust. This provides some assurance that low-trust countries are not simply taking the test less seriously. To further establish the suitability of the $d$ score as measure of the division of labor we consider it in a context with a strong theoretical underpinning: a between country regression of GDP on d provides evidence that the division of labor is, in fact, associated with the wealth of nations $(p<.05)$.

\section{Appendix III: Between-country analysis of Trust and the Division of Labor}

Table 2 of the main text showed the positive relationship of a country's level of trust to its division of labor. In the following table we revisit this finding using between country models and the d-score (Table A.2). Model 2 exhibits a Tobit regression to account for censoring that 0 that may occur in our dependent variable when the data is analyzed at the industry level. Models 1 and 3 use a multivariate OLS with clustering at the country-industry (1) level and the country (3) level. The relationship between $d$-score and trust is, again, positive and significant and robust to controls ${ }^{29}$.

\footnotetext{
${ }^{29}$ Just as in Table 2 these are: number of industries per country, logged GDP, logged Population, government consumption, openness, and fuel consumption.
} 
TABle A.2-TRUST AND “d” AdDitional Models

\begin{tabular}{llll}
\hline \hline & $(1)$ & $(2)$ & $(3)$ \\
Dependent Variable & $d$ & $d$ & $d$ \\
\hline Log Trust & $0.0836^{* * *}$ & $0.0883^{* * *}$ & $0.0891^{* *}$ \\
& $(0.0221)$ & $(0.0237)$ & $(0.0418)$ \\
Controls & $\mathrm{Y}$ & $\mathrm{Y}$ & $\mathrm{Y}$ \\
Constant & $0.420^{* * *}$ & $0.399^{* * *}$ & $0.426^{* *}$ \\
& $(0.0749)$ & $(0.0803)$ & $(0.173)$ \\
\hline $\mathrm{N}$ & 7589 & 7589 & 138 \\
\hline \hline
\end{tabular}

Note: Results from an OLS multiple regression (1 and 3), and a Tobit regression (2). Robust errors clustered at the domestic industry (1 and 2) and country (3) levels.

$* * * \mathrm{p}<0.01, * * \mathrm{p}<0.05, * \mathrm{p}<0.1$

Of particular concern in between countries analysis of $d$ is the possibility that industry differences are driving the division of labor difference. Accordingly, we use our industry-differenced $d$-score ("diffd") to evaluate this possibility. Table A.3 finds similarly positive and significant results using a multiple OLS (1 and 3) and a Tobit (2) with diffd as the dependent variable.

TABle A.3-TRUST AND “diffd” AdDitional Models

\begin{tabular}{llll}
\hline \hline & $(1)$ & $(2)$ & $(3)$ \\
Dependent Variable & diffd & diffd & diffd \\
\hline Log Trust & $0.0784^{* * *}$ & $0.0364^{* * *}$ & $0.0870^{* *}$ \\
& $(0.0186)$ & $(0.00858)$ & $(0.0391)$ \\
Controls & $\mathrm{Y}$ & $\mathrm{Y}$ & $\mathrm{Y}$ \\
Constant & $-0.433^{* * *}$ & $-0.223^{* * *}$ & $-0.449^{* *}$ \\
& $(0.0637)$ & $(0.0286)$ & $(0.162)$ \\
\hline $\mathrm{N}$ & 7589 & 7589 & 138 \\
\hline \hline Note: Results from an OLS multiple regression (1 and 3), and a Tobit \\
regression $(2)$. Robust errors clustered at the domestic industry (1 and 2) and \\
country (3) levels. \\
*** $\mathrm{p}<0.01,{ }^{* *} \mathrm{p}<0.05,{ }^{*} \mathrm{p}<0.1$
\end{tabular}

Figure A.1 displays an equivalent graph to Figure 8 in the main text, but using diffd as the dependent variable. A similar linear trend is observed. 


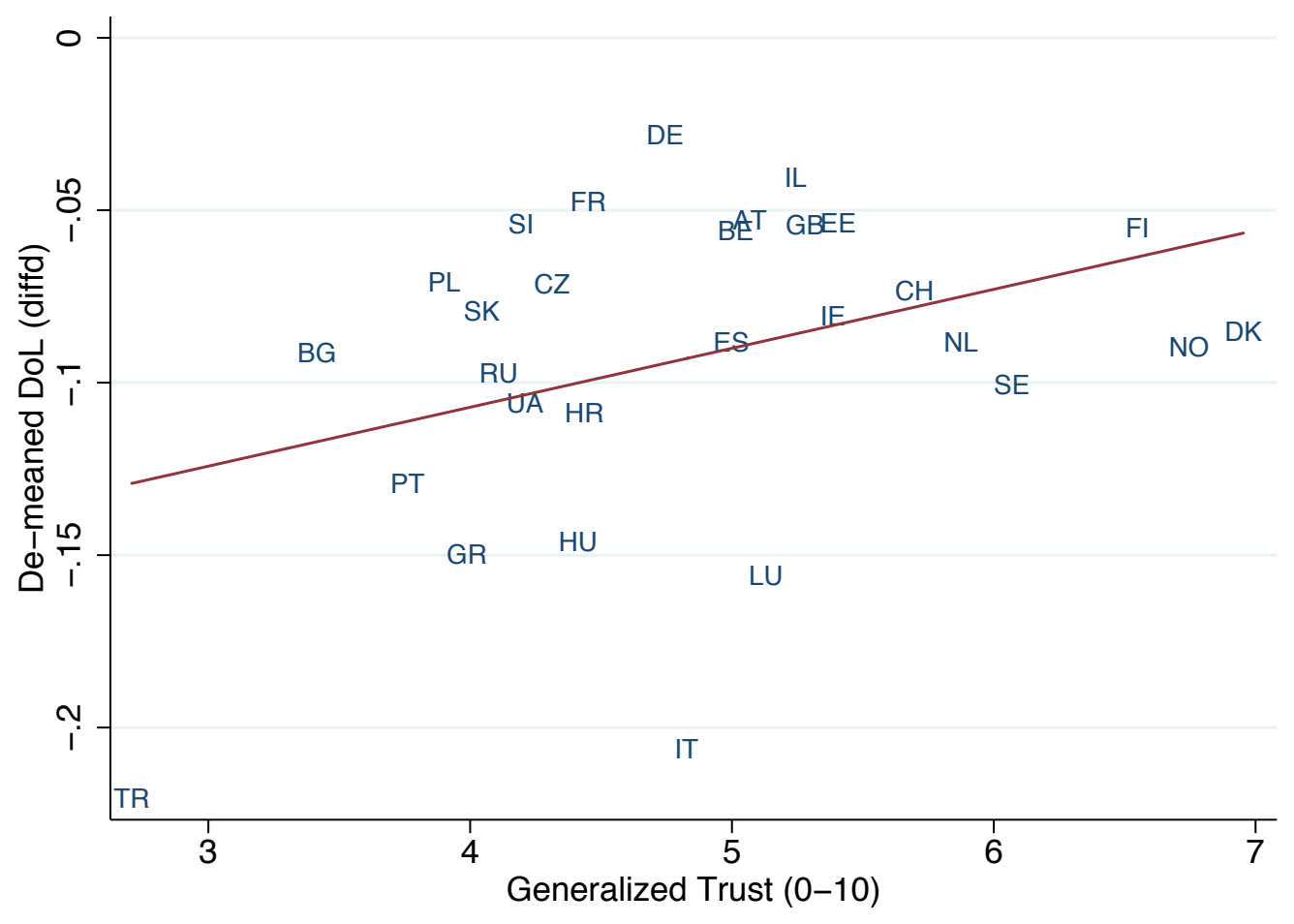

Note: Data taken from European Social Survey and measures averaged across countries from 2002-2012. Plot omits graphical outliers Cyprus (CY), Israel (IS), and Kosovo (XK). These countries are not omitted from the statistical analysis

FIGURE A.1: TRUST AND DE-MEANED DIVISION OF LABOR (“DIFFD”) 


\section{Appendix IV: A game theoretic illustration of our theory}

This model is adapted from the set-up in Becker \& Murphy (1992), in which workers incur coordination costs as a result of specialization in complementary tasks. Within the model $\theta$ and $\mathrm{c}$ will be primitives where $\theta$ is the productive potential of the two individual's complementary skills and $\mathrm{c}$ is the relative deficiency of each member's skills in her less-preferred task. Whereas Becker \& Murphy focus on "learning-by-doing"-which we agree is a major factor in successful specialization-we restrict our attention to a situation in which specialization has already occurred and we thus take $\theta$ as exogenous. Overall productive output is represented by $\mathrm{Y}$ and the utility which accrues to each agent for choosing their outside option is denoted by parameter $\mathrm{r}$. The values are assumed to be symmetric across the individuals, noting only the difference in their skills for a particular type of task (a loss of $\mathrm{c}$ when individual $\mathrm{i}$ chooses task $\mathrm{j}$ and vice versa). In effect, we are modeling a situation in which two workers, specialized in distinct but complementary skills, decide whether to specialize, generalize, or take the outside option. ${ }^{30}$ For concision we illustrate the game as taking place between two agents participating in team production. The game is played as a simultaneous move game with a productive process adapted from Becker \& Murphy (1992) as follows:

$$
\mathrm{Y}=\min \left\{\theta \sum_{\mathrm{i}} \mathrm{y}_{\mathrm{i} 1}-\mathrm{cy}_{21} \quad, \quad \theta \sum_{\mathrm{i}} \mathrm{y}_{\mathrm{i} 2}-\mathrm{cy}_{12}\right\}
$$

This says the production is determined by the minimum amount of effort, summed over agents $i$ and $j$, in either of the two tasks. The effort is scaled by an agent's productivity $\theta$ (assumed equal for simplicity) and subject to a cost of non-specialist effort $c$ as when agent 1 works on task 2 and vice versa. Each agent receives a half-share of the full production plus their private gains realized from the outside task $y_{R}=r: \pi_{i}=Y / 2+r_{i}$.

Individual strategies $s_{i} \in S=\left\{s_{i}, s_{j}, s_{k}\right\}$ have the following effect on production: $s_{i}$ sets $y_{i i}=1, s_{j}$ sets $y_{i i}=.5$ and $y_{i j}=.5$, and $s_{k}$ sets $y_{i R}=1$. For our application, these strategies are

\footnotetext{
${ }^{30} \mathrm{We}$ assume ex ante uncontractibility of the production or effort choices, due perhaps to "metering problems" or the inability of the parties to specify the other's tasks. We also assume that ex post excludability from productive gains is not possible, though this assumption can be relaxed.
} 
most intuitively thought of as Work, Generalize and Renege and will be presented thus. W $\left(\mathrm{s}_{\mathrm{i}}\right)$ is the generalist strategy in which the agent only works on the specialized subtask, $G\left(s_{j}\right)$ is the generalist strategy in which each agent works fully and evenly on the entire task including the non-specialized subtask, and $\mathrm{R}\left(\mathrm{S}_{\mathrm{k}}\right)$ takes the outside option. The payoffs from the game are in Figure A.2.

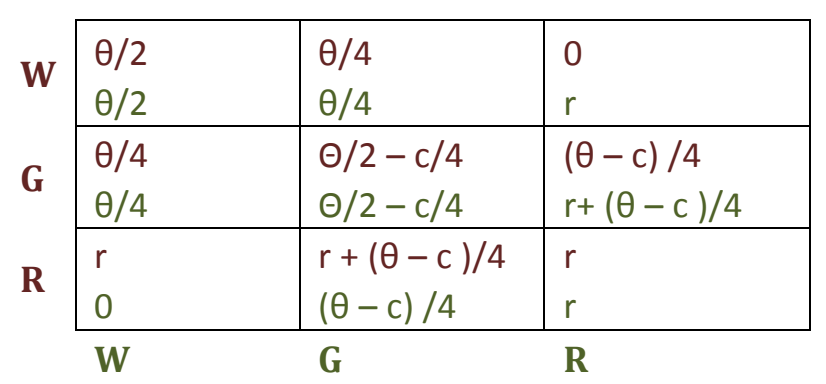

FIGURE A.2 PAYOFFS FOR A DIVISION OF LABOR COORDINATION GAME

We restrict $0<\mathrm{r}, \mathrm{c}<\theta / 2$, suggesting gains from the outside option, costs to generalist production, and potential benefits for specialist coordination within the firm. Parameter $r$ is allowed to vary within this constraint and, informally, we can think of it as expressing the outside offers for one's productive skillset net of some costs. Thus $\mathrm{r}$ may increase as market matures and additional firms demand one's skillset.

We restrict attention to pure strategy Nash equilibria of the one-shot game, and term the three pure strategy equilibria as follows: W,W is the "specialist equilibrium", G, G is the "generalist equilibrium" and R,R is the "outside equilibrium". Note that G,G and R,R are only equilibria for some value of $r$. Given the conditions on $r$ providing for gains to specialization, WW is always the payoff dominant Nash Equilibrium of the game. If $r<\frac{(\theta-c)}{4}$ the game is simply one of coordination between the specialist and generalist equilibria with payoff dominance favoring the specialist equilibrium. As the market matures and $\mathrm{r}$ increases there exists an $r$ such that all coordinated activities are equilibria. This occurs when $0<\frac{\theta-c}{4} \leq r \leq \frac{\theta}{4}$. For illustrative purposes, figure A. 3 shows one such parameterization with $\theta=40, c=4, r=9$ : 


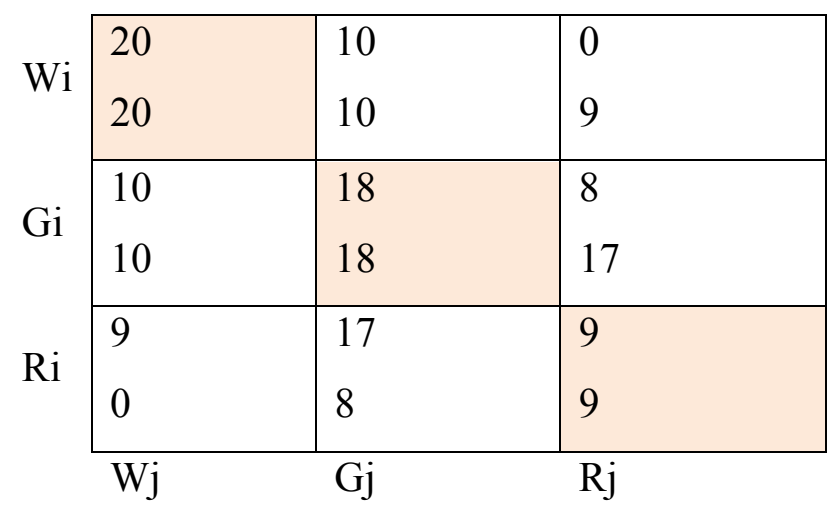

FIGURE A.3. THE PARAMETERIZED DIVISION OF LABOR GAME

While the equilibrium payoffs resemble a classic minimum effort game, the off-equilibrium payoffs are distinct and highlight the role of belief in this game. WW is payoff dominant just as it would be in an equivalent minimum effort game, however GG and RR are distinct due to the productive process adapted from Becker \& Murphy: RR is maximin, and GG is a best response to random play (BRU). An uninformative (uniform) prior over the counter-party's selection of strategies produces best response $\mathrm{G}$, whereas increasing the prior belief on the play of $\mathrm{W}$ above .5 (with the beliefs in $\mathrm{G}$ and $\mathrm{R}$ decreased proportionally) produces best response $\mathrm{W}$.

Accordingly, our model outlines the selection of generalist equilibria and specialist equilibria as a response to beliefs about one's counter-party. This result is related to Goyal \& Janssen's model of "flexibility" in a repeated assurance game (1997), though in their model the flexible action ensures maximal coordination and is not itself an equilibrium of the stage game. 


\section{Appendix V: Supplementary experimental analysis}

In the main text we exclude "monitoring switches" from our analysis because we believe they are less relevant to the functional division of labor in groups. These are switches in which individuals click "switch" but then do not work on another's field, and thus there is no actual task overlap. Nevertheless we include these switches in table A.4 to show that our results are robust to them.

\begin{tabular}{|c|c|}
\hline Dependent Variable & \# of ALL Switches \\
\hline High Trust (=1) & $\begin{array}{c}-1.08 * * \\
(0.478)\end{array}$ \\
\hline Round & $\begin{array}{c}-0.766^{* *} \\
(0.276)\end{array}$ \\
\hline High Trust $\times$ Round & $\begin{array}{c}0.342 \\
(0.323)\end{array}$ \\
\hline Constant & $\begin{array}{l}1.9 * * * \\
(0.381)\end{array}$ \\
\hline $\begin{array}{l}\text { R-squared } \\
\mathrm{N}\end{array}$ & $\begin{array}{c}0.190 \\
126\end{array}$ \\
\hline
\end{tabular}

